\title{
Evidence for Premotor Cortex Activity during Dynamic Visuospatial Imagery from Single-Trial Functional Magnetic Resonance Imaging and Event-Related Slow Cortical Potentials
}

\author{
Claus Lamm, ${ }^{*}$ Christian Windischberger, $\dagger$ Ulrich Leodolter, ${ }^{*}$ Ewald Moser $\uparrow \uparrow$ and Herbert Bauer* \\ *Brain Research Laboratory, Department of Psychology, $\dagger$ NMR group, Institute for Medical Physics, and $\ddagger$ Department of Radiology, \\ Hospital of the University of Vienna, University of Vienna, Vienna, Austria
}

Received September 11, 2000

\begin{abstract}
A strong correspondence has been repeatedly observed between actually performed and mentally imagined object rotation. This suggests an overlap in the brain regions involved in these processes. Functional neuroimaging studies have consistently revealed parietal and occipital cortex activity during dynamic visuospatial imagery. However, results concerning the involvement of higher-order cortical motor areas have been less consistent. We investigated if and when premotor structures are active during processing of a three-dimensional cube comparison task that requires dynamic visuospatial imagery. In order to achieve a good temporal and spatial resolution, single-trial functional magnetic resonance imaging (fMRI) and scalp-recorded event-related slow cortical potentials (SCPs) were recorded from the same subjects in two separate measurement sessions. In order to reduce inter-subject variability in brain activity due to individual differences, only male subjects $(n=$ 13) with high task-specific ability were investigated. Functional MRI revealed consistent bilateral activity in the occipital (Brodmann area BA18/19) and parietal cortex (BA7), in lateral and medial premotor areas (BA6), the dorsolateral prefrontal cortex (BA9), and the anterior insular cortex. The time-course of SCPs indicated that task-related activity in these areas commenced approximately 550-650 ms after stimulus presentation and persisted until task completion. These results provide strong and consistent evidence that the human premotor cortex is involved in dynamic visuospatial imagery. $\odot 2001$ Academic Press
\end{abstract}

\section{INTRODUCTION}

A considerable number of functional neuroimaging studies have examined the neural bases of dynamic visuospatial imagery, such as mental rotation (Shepard and Metzler, 1971). The most consistent finding was that task solving evokes activity in the parietal cortex, particularly the superior parietal lobe. Results concerning the involvement of higher-order motor areas, such as the lateral and medial premotor cortex, have been less consistent. While Cohen et al. (1996) found premotor activity (with no differentiation of lateral and medial parts) in only some of their subjects (four of eight in the left and three of eight in the right hemisphere), Richter et al. (2000) demonstrated consistent premotor activity during mental rotation using time-resolved fMRI. On the other hand, a recently published fMRI study (Jordan et al., 2001), and two recent positron emission tomography studies (PET; Kosslyn et al., 1998; Harris et al., 2000), did not report any premotor cortex activity during mental rotation of both two-dimensional and three-dimensional objects.

Several studies using dual-task paradigms indicate a strong interference between the performance of rotational movements and mental rotation (Wexler et al., 1998; Wohlschläger and Wohlschläger, 1998), and Pellizzer and Georgopoulos (1993) demonstrated that explicit and imagined object rotation share common processing constraints. It has also long been postulated that dynamic imagery and overt movements are functionally equivalent (Bain, 1855; James, 1890; Weimer, 1977; Scheerer, 1984; Prinz, 1997). Since this would imply that both processes draw upon similar or identical neural resources, we hypothesized that not only parietal, but also lateral and medial premotor areas should be consistently active during dynamic visuospatial imagery.

Inconsistencies in the results of earlier studies concerning premotor cortex involvement may have been partly due to differences in the spatial and temporal resolution of the imaging methods and paradigms used. Thus, in order to assess cortical activity during dynamic visuospatial imagery with sufficient temporal and spatial resolution, we performed a multimodality study. Multislice single-trial fMRI was used to acquire images of task-related hemodynamic changes with high spatial resolution and good temporal resolution. In addition event-related slow cortical potentials 
(SCPs) were recorded from the scalp of the same subjects in a separate measurement session. SCPs allowed the examination of the time-course of cortical activity in the subseconds range. Since SCPs are related to sustained excitatory input to apical dendrites of cortical pyramidal cells, they also provided a more direct assessment of neural activity than fMRI-derived measurements (Bauer, 1998; Rösler et al., 1997; Birbaumer et al., 1990). Hence SCPs might help to resolve the ambiguity that increased blood flow or oxygenation may be equally related to increased activity of either excitatory or inhibitory neurons. In order to overcome some of the potentially confounding variables of other studies we controlled several behavioral parameters, including the type and consistency of task-processing strategy used, the homogeneity of the sample investigated, and the task presentation mode.

\section{MATERIAL AND METHODS}

\section{Subjects}

Thirteen young healthy volunteers with no history of neurological or psychiatric disorders and normal or corrected to normal vision participated in one SCP and one MRI/fMRI measurement session. The order of the sessions was balanced and the time separating the two session orders was kept constant across subjects. Written informed consent was obtained prior to measurements and subjects were paid $\sim 7.50 €$ per hour for their participation. All subjects were right-handed according to the Marian Annett handedness inventory (Annett, 1985).

Ability-dependent differences in cortical activity during cognitive processing have been repeatedly reported, with poor performers showing increased cortical activity during task solving (Haier et al., 1988; Lamm et al., 1999). In order to exclude the confounding effects of such individual differences, potential participants were pretested using a standardized three-dimensional cube comparison test (3DC; Gittler, 1990). Only subjects with high task-specific ability who solved at least 15 of the 17 test items (corresponding to the 4th performance quartile of the age-, sex-, and education-specific calibration sample of the test) of the 3DC were selected for this study. As a result of this pretesting procedure, all subjects had the same prior experience in performing the tasks used in the experiments.

The homogeneity of the sample was further increased by investigating only male subjects (since gender differences in visuospatial processing are well-documented; see, e.g., Voyer et al., 1995), by restricting the subjects' age range (mean 24.5 years, range: 19-28), and by keeping the sample homogenous with respect to verbal and general intelligence (IQ 101-129, deter- mined by using a brief word power test; Schmidt and Metzler, 1992).

\section{Task Material}

The task material was an adaptation of the 3DC test used for subject selection. The decision to use 3DCderived tasks in the investigation of dynamic visuospatial imagery was based on several favorable attributes of the test. Psychometric properties, such as reliability and validity, are well-known and high and have been determined using large calibration samples (Gittler, 1990). This is in contrast to most task material used in functional neuroimaging of cognition where face validity is sometimes the only known psychometric quality. In addition, 3DC tasks allow the assessment of visuospatial imagery with increased intra- and interindividual homogeneity since they fulfill the criteria of the Rasch model (Rasch, 1980). Tasks which conform to this probabilistic model allow unidimensional measurements of cognitive abilities, which implies that identical cognitive processes are active in all tasks as well as in different groups of subjects. This is an advantage compared to, e.g., two-dimensional letter or object comparison tests where some tasks do not require any mental rotation of stimuli (Corballis et al., 1978; Cohen and Kubovy, 1993) and where some subjects might use predominantly verbalization rather than visuospatial strategies.

For our study (where subjects processed up to 170 tasks in the two separate measurement sessions), it was also of particular importance that 3DC tasks show minimal practice-related changes in processing strategy. Such changes have been observed when using Shepard-Metzler figures (Shepard and Metzler, 1971), whereby subjects with sufficient practice may use stored representations of the $3-\mathrm{D}$ objects to decide about their identity rather than rotating the objects (Tarr and Pinker, 1989). Such a change in strategy had to be avoided in our study since subjects should not use different processing strategies and associated brain activity in the two consecutive measurement sessions.

Another important feature of the tasks used in the present study is their long response times, ranging from $5 \mathrm{~s}$ up to $2 \mathrm{~min}$ with a median around $14 \mathrm{~s}$. These rather long response times are in contrast to those obtained with Shepard-Metzler figures and most other mental rotation paradigms in which tasks with low angular difference can be answered within 1 or $2 \mathrm{~s}$. Such short response times make it more difficult to separate cognitive processes related to visuospatial imagery from processes related to response preparation and execution.

\section{Task Design}

Each trial consisted of a baseline image (white crosshair placed between two blue cubes without any 


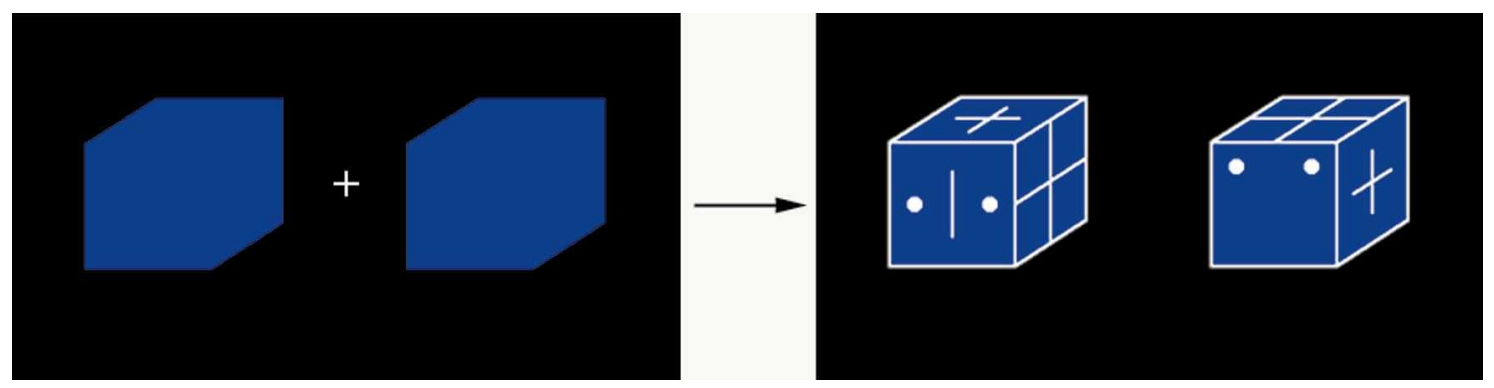

FIG. 1. Sample of the tasks used in this study. Following button press, the baseline image (white crosshair between two blue cubes without graphic elements on a black background) was replaced by a task stimulus consisting of two cubes with white graphic elements on three of their faces. Subjects had to decide whether these cubes could be identical (which is the case for the sample shown). The images were displayed centered in the middle of a computer screen (SCP) or of video goggles (MRI), respectively.

graphic elements or white edges) and a task stimulus (see Fig. 1). Subjects initiated each trial by pressing a button, after which the baseline image was replaced by a task stimulus. The stimuli consisted of two blue cubes with white graphic elements (triangles, dots, squares, arrows, etc.) on each of their three visible faces presented simultaneously on a black background. Subjects had to decide whether or not the two cubes could picture one and the same cube and to respond by pressing one of two response buttons with their dominant right hand (answers "yes" or "no"). Subjects were explicitly instructed that they had to decide only whether the two cubes could be identical, keeping in mind that each graphic element was allowed to occur only once on each cube. Without this instruction, the fact that three sides of each cube were not visible would allow any two cube configurations to be showing the same cube. A correct understanding of the instruction and the task content was ascertained by several sample tasks.

The widely used instruction to answer as quickly and accurately as possible affects unidimensionality (Rasch, 1980) and evokes processes not specifically attributable to the particular cognitive task, such as increased effort and working memory demand (Gulliksen, 1965). Since it has been shown that this results in increased cortical activity (Lamm et al., 2001), task presentation time was not restricted in the present study and subjects were told they would have ample time to solve each task. The task presentation and data acquisition mode for SCP and fMRI-measurements were completely identical (except for the minimum intertrial interval and the display device) in order to enhance the comparability of the behavioral and neuroimaging results obtained by the two different methods. The tasks used in the SCP and fMRI sessions were partially identical, since only a limited number of standardized and calibrated 3DC items exist. However, since their presentation order was randomized across subjects and since all tasks look very similar, distinguishable only by the type and orientation of the graphic elements on the cube faces, it is unlikely that subjects remembered tasks presented in the first measurement session.

\section{MRI and fMRI Scanning}

MRI experiments were performed in a 3 Tesla Medspec S300 tomograph (Bruker Medical, Ettlingen, Germany) equipped with a whole-body gradient system and a standard birdcage coil for RF excitation/reception. An anatomically formed cushion and a strap around the forehead were used to reduce gross head motion. Structural images of the brain were acquired using a 64 slice FLASH sequence with $1 \times 1 \mathrm{~mm}$ in-plane resolution and a slice thickness of $3 \mathrm{~mm}$. A T2*-weighted single-shot, blipped gradient-recalled EPI sequence (flip angle = Ernst angle) with a matrix size of 64 by 64 pixels, an echo time (TE) of $23 \mathrm{~ms}$ and a readout bandwidth of $100 \mathrm{kHz}$ was used for functional imaging. 15 axial slices with a FOV of 190 by 190 $\mathrm{mm}$, a thickness of $5 \mathrm{~mm}$, and an interslice gap of $1 \mathrm{~mm}$, covering nearly the whole cerebrum, were acquired. Repetition time (TR) for the whole image slab was $1.5 \mathrm{~s}$. The single-trial sequence was designed to ensure continuous data acquisition and constant intervals between images. Two runs of $15 \mathrm{~min}$ each $(600$ images/slab) were acquired, each starting with $30 \mathrm{~s}$ of dummy scans to allow for steady state conditions. Although the task content and task difficulty were the same in the two runs, their sequence was balanced across subjects.

Stimuli were presented via MRI-compatible video goggles (Resonance Technologies, Northridge, CA) con-

\section{TABLE 1}

Processing Time (s) and Response Accuracy in the SCP and fMRI Measurement Session (mean \pm SD)

\begin{tabular}{lcc}
\hline & Processing time & $\begin{array}{c}\text { Percentage of correctly } \\
\text { answered tasks }\end{array}$ \\
\hline SCP & $11.91 \pm 4.99$ & $96.71 \pm 2.59$ \\
fMRI & $16.42 \pm 7.24$ & $91.58 \pm 4.87$ \\
\hline
\end{tabular}



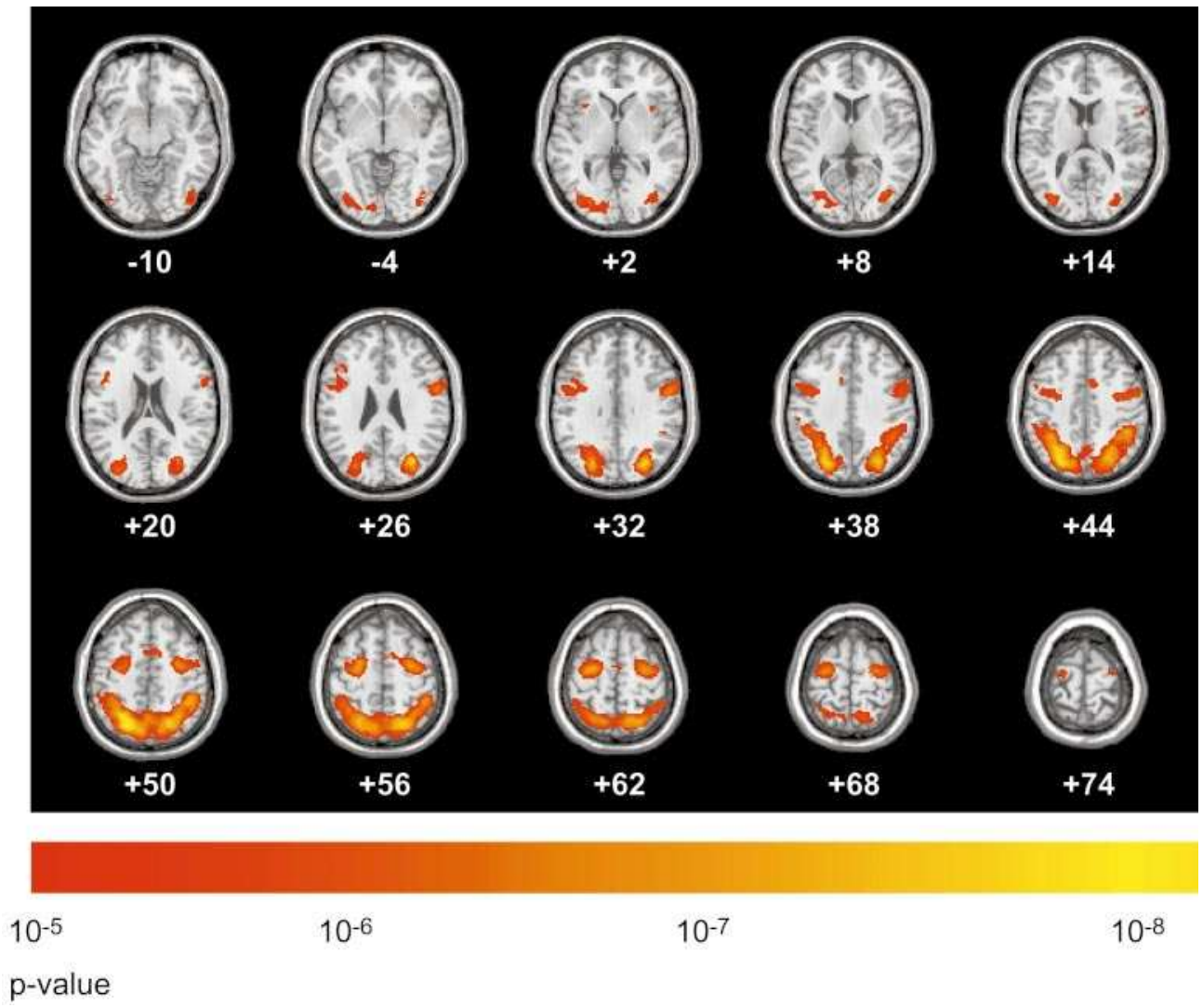

FIG. 2. Grand mean fMRI activity during task processing. Color-coded $P$ values (thresholded at a value of $P=0.00001$, uncorrected) are overlaid upon high-resolution structural MR images (neurological convention, left = left) in stereotactic space (Montreal Institute of Neurology). Yellow indicates higher $P$ values (see color scale). Values below slices indicate $z$ coordinates in stereotactic space.

nected to the video output of a controlling PC running in-house software for stimulus presentation. The visual angle subtended by the two cubes $\left(\sim 1.64^{\circ}\right.$ vertical, $\sim 8^{\circ}$ horizontal) was kept as low as feasible in order to reduce the requirement of making large saccadic eye movements. The buttons for responses and task initiation were mounted on a board attached to the subject's right thigh. The minimum intertrial interval was $20 \mathrm{~s}$ in order to allow cerebral blood flow changes to return to baseline between trials.

\section{fMRI Analysis}

The structural MR images were normalized to the average brain template of the Montreal Institute of Neurology (MNI) using the software package SPM99 (Friston et al., 1995; The Wellcome Department of Cognitive Neurology, London, UK). Functional images were corrected for head motion in $2 \mathrm{D}$, using sinc-interpolation (AIR v3.08; Woods et al., 1998), and coregistered to the normalized structural images via linear translation and stretching of the functional images using IDL routines (Interactive Data Language; Research Systems, Inc., Boulder, CO) written in-house. The accuracy of normalization and coregistration was carefully checked for each subject based on several brain landmarks and the shape of the slices.

The functional images were spatially smoothed with a Gaussian kernel of $9 \mathrm{~mm}$ full-width-at-half-maximum. The main reason for applying spatial smoothing was to reduce the effect of interindividual differences in both structural and functional neuroanatomy. Since a Gaussian kernel was used, the assumption that data were normally distributed also seems to be more valid than without smoothing (see Friston et al., 1995). This was decisive for the validity of the subsequent statistical tests.

Task-related changes in single trials were assessed by computing $t$ tests contrasting the signal intensity during task processing with the signal intensity during baseline. A $t$ test was preferred to a computation of the mean signal change between baseline and task processing since it takes account of the variance across pixels. For each pixel of each single trial of each subject a $t$ value was obtained and then a $t$ test (one-sided) of these single trial $t$ values was performed. The reason for performing such a $t$ test was to get a summary statistic of the activity of all single trials. The resulting $t$ values were color- 
TABLE 2

Neuroanatomical Localization, Stereotactic Coordinates (MNI-Space, Local Maximum Voxel), Brodmann Area (BA), and Consistency of Significant fMRI Activity Clusters during Task Processing

\begin{tabular}{|c|c|c|c|c|c|}
\hline \multirow[b]{2}{*}{ Anatomical brain region } & \multirow[b]{2}{*}{ BA } & \multicolumn{3}{|c|}{ Coordinates } & \multirow[b]{2}{*}{ Consistency } \\
\hline & & $x$ & $y$ & $z$ & \\
\hline L Occipital & $18 / 19$ & -26 & -82 & 2 & $13 / 13$ \\
\hline R Occipital & $18 / 19$ & 38 & -78 & 6 & $13 / 13$ \\
\hline L Superior parietal & 7 & -24 & -58 & 52 & $13 / 13$ \\
\hline R Superior parietal & 7 & 22 & -64 & 54 & $13 / 13$ \\
\hline Medial superior frontal gyrus & 6 & 10 & 8 & 52 & $13 / 13$ \\
\hline L Precentral gyrus & 6 & -28 & -10 & 64 & $13 / 13$ \\
\hline $\mathrm{R}$ Precentral gyrus & 6 & 30 & -6 & 56 & $13 / 13$ \\
\hline L Dorsolateral prefrontal cortex & 9 & -48 & 4 & 28 & $13 / 13$ \\
\hline R Dorsolateral prefrontal cortex & 9 & 56 & 4 & 28 & $13 / 13$ \\
\hline L Insular cortex & & 36 & 14 & 2 & $11 / 13$ \\
\hline $\mathrm{R}$ Insular cortex & & -32 & 18 & 2 & $11 / 13$ \\
\hline
\end{tabular}

coded and mapped on to the structural images. A thresholding procedure had to be applied in order to identify regions of significant activity (see also the discussion below). Maps were thresholded at a $t$ value corresponding to a $P$ value of 0.00001 (for each single voxel, i.e., uncorrected for multiple comparisons), and significant activity clusters and their peak voxels were identified for each subject. In order to assess activity in the whole sample, the 13 singlesubject $t$ maps were averaged in stereotactic space. The resulting grand mean fMRI activity map was thresholded at a $t$ value corresponding to $P=$ 0.00001 (for each single voxel).

Both the fMRI grand mean activity and the consistency of activity determined on the basis of singlesubject activity maps are reported. While the former allows inferences about "average" characteristics, the latter allows inferences about "typical" characteristics of brain activity in the sample investigated (Friston et al., 1999). Anatomical locations and Brodmann areas

\section{TABLE 3}

Areas and Consistency of Significant SCP Activity during Task Processing

\begin{tabular}{ll}
\hline \multicolumn{1}{c}{ Scalp region } & Consistency \\
\hline L occipital & $12 / 13$ \\
R occipital & $12 / 13$ \\
L parietal & $13 / 13$ \\
R parietal & $12 / 13$ \\
L frontocentral & $13 / 13$ \\
R frontocentral & $13 / 13$ \\
Medial frontocentral & $10\left(13^{a}\right) / 13$ \\
L frontolateral & $11 / 13$ \\
R frontolateral & $11 / 13$ \\
\hline
\end{tabular}

\footnotetext{
${ }^{a}$ Instead of a clear medial frontocentral current sink, three of the subjects showed two medial bilateral current sinks over the frontocentral region.
}

(BA) of significant activity clusters were determined using the brain atlas published by Talairach and Tournoux (1988) and a digitized Talairach atlas (http:// biad73.uthscsa.edu; Lancaster et al., 2000).

\section{EEG Recording}

The EEG was recorded using a 24-channel DC amplifier with high baseline stability and an input impedance $\geq 100 \mathrm{G} \Omega$. Signals were sampled at $125 \mathrm{~Hz}$ and recorded within a frequency range from DC to $30 \mathrm{~Hz}$. Variable signal epochs covering $2 \mathrm{~s}$ of prepresentation baseline to two seconds after response were stored trial by trial. The EEG was recorded using $40 \mathrm{Ag} / \mathrm{AgCl}$ EEG electrodes attached to small plastic adapters that were fixed to the subject's scalp with collodion. Recording sites were skin-scratched with sterile single-use needles (Picton and Hillyard, 1974) to minimize skin potential artifacts and to keep electrode impedance homogeneous, stable, and below $1 \mathrm{k} \Omega$ (which was confirmed for each electrode separately). Degassed electrode gel (Electro-Gel, Electrode-Cap International, Inc., Eaton, $\mathrm{OH}$ ) was used, and electrodes were filled with the gel at least half an hour before application to allow for stabilization of the electrode potential. A noncephalic sternovertebral reference (Stephenson and Gibbs, 1951) was used for all EEG channels. It consisted of two electrodes, one placed at the 7 th cervical vertebra and the other at the right sternoclavicular junction. A $5 \mathrm{k} \Omega$ potentiometer connecting these two electrodes was individually adjusted to minimize electrocardiographic components in the EEG. Vertical (electrodes above and below the right eye) and horizontal (electrodes on outer canthi) electrooculograms (VEOG, HEOG) were recorded bipolarly to check for eye movement artifacts.

Since the DC amplifier had only 24 channels, the EEG was alternately recorded from two interleaved electrode sets, with each set consisting of 20 EEG elec- 
trodes and of two electrodes placed on the mastoids. The electrodes of both sets were distributed equally across the scalp surface. With each electrode set at least two blocks of 30 trials were recorded. The sequence of blocks was randomly permuted across subjects. 3-D coordinates of all EEG electrodes, and of nasion, inion, and the two preauricular points were measured using a photogrammetric head digitizer (Bauer et al., 2000). The tasks were presented in the center of a computer screen located approximately 70 $\mathrm{cm}$ in front of the subject, and a response board was positioned to the right of the subject. The visual angle subtended by the stimuli was approximately identical to that used for the fMRI goggles. The minimum intertrial interval was $4 \mathrm{~s}$.

\section{EEG Analysis}

Eye movement artifacts were eliminated offline using a linear regression algorithm (see Vitouch et al., 1997, for a detailed description). All trials were visually screened to exclude those containing artifacts. Stimulus-onset linked averages were computed for each subject. The mean amplitude in the 200-ms epoch preceding task presentation served as the prestimulus baseline. Since response times were variable within and across subjects, an analysis epoch of five seconds was selected based on the median reaction times. This epoch length was chosen because it was long enough to reliably induce cognition-related SCPs and because only a few trials had to be rejected due to response times shorter than five seconds (see also Lamm et al., 2001). In order to exclude activity related to motor preparation and execution of the button press, only trials with response times $\geq 5500 \mathrm{~ms}$ were included in the averages. In addition, response-linked averages (with the same $200 \mathrm{~ms}$ prestimulus baseline as for the stimulus-linked averages) were computed to evaluate activity related to task completion and response execution.

SCP averages and their current source density (CSD) transforms were topographically mapped using the analytical interpolation algorithm proposed by Babiloni et al. (1996). CSD transformation was carried out in order to yield reference-free maps and to attenuate low spatial frequencies ("smearing") introduced into the scalp potential distribution due to volume conduction (Nunez, 1989; Nunez et al., 1994; Srinivasan et al., 1996). In order to map the activity distribution on the scalp surface with increased spatial sampling (Nunez et al., 1994; Srinivasan et al., 1998), the data of the two electrode sets were used simultaneously for the interpolation. SCP and CSD maps were visualized on individual head shapes reconstructed by using spline interpolation of the 3-D electrode and landmark coordinates acquired by the photogrammetric head digi- tizer. The accuracy of this approach was guaranteed by coregistration with MRI-reconstructed head shapes which yielded a mean deviation between EEG- and MRI-derived surface points of only $2.3 \mathrm{~mm}$ (Lamm et $a l ., 2000)$. Coregistration was also used to determine the position of electrodes in relation to individual cortical anatomy. Grand mean SCP and CSD maps (Fig. 5 ) were computed using the mean electrode coordinates of the whole sample for interpolation. The consistency of activity across subjects was assessed by comparing individual-subject averages with the grand mean. SCP and CSD maps and SCP waveforms were used to assign surface activity to cortical areas that were detected to be active by means of fMRI.

\section{Behavioral Data and Questionnaire}

Median processing time and percentage of correctly answered tasks were calculated separately for the SCP and MRI sessions. In addition, two questionnaires that had been specifically designed for this study were completed by each subject. These were used to gain information about the subjects' task solving strategies. Questionnaire A included questions about the task difficulty, the effort and concentration invested by the subjects, the percentage of items they were convinced to have answered correctly, and how motivated they felt during the experiment. Questionnaire A was presented twice, i.e., after the SCP as well as after the MRI session.

As discussed above, 3DC tasks are known to show relatively fewer intra- and interindividual differences in processing strategies than tasks which do not conform to the Rasch model. However, since such differences cannot be precluded in any type of cognitive task processing, questionnaire B assessed two possible task solving strategies. The most commonly used strategy consists almost exclusively of dynamic visuospatial imagery and mental rotation. The second strategy is a more analytical one and includes verbal-analytical descriptions of the relations of the cubes and their graphic elements. Nevertheless, it also relies on visuospatial cognition because the cubes and the mutual relations of their graphic elements are coded and compared using spatial descriptors (such as "the arrow on the upper face of the left cube points to the left anterior corner of this cube"; see also Gittler, 1990). By using the standardized written task instruction of the 3DC test special care was taken not to bias subjects in favor of either of the two strategies (Intions-Peterson, 1983). Since a presentation after the first session might have influenced the subjects' processing strategies in the second session, questionnaire B was presented only once and always after the second measurement session. 

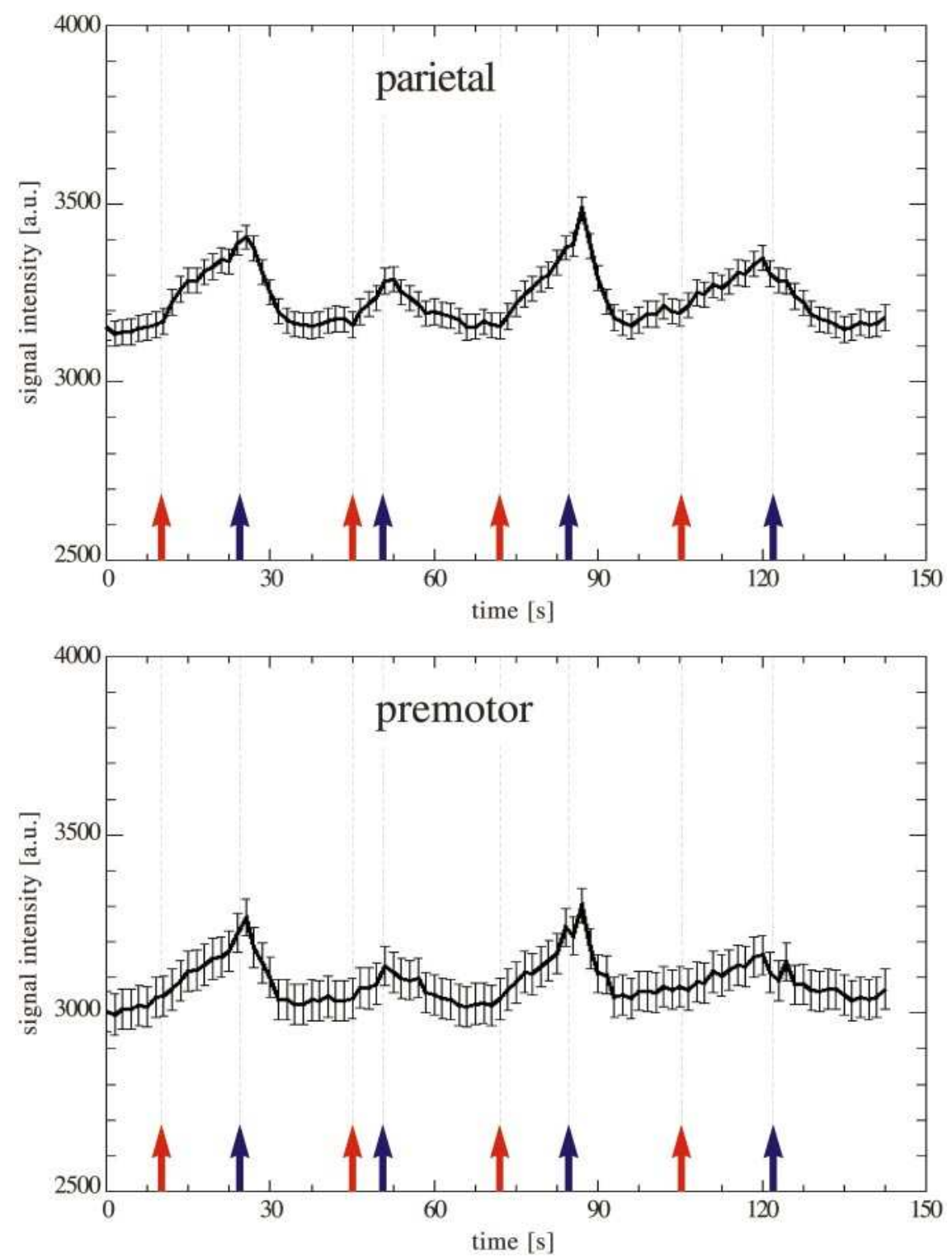

FIG. 3. Changes in signal intensity (arbitrary units, mean \pm SE) of one subject for selected parietal and premotor pixels contingent upon task processing and task response. Task presentation and response are marked by red and blue arrows. Note the almost identical onset and peak time of signal increases in the two brain regions.

\section{RESULTS}

\section{Behavioral Data}

Performance. On average, 94.14\% (range 88.9997.28) of the tasks were answered correctly. Average processing time was $14.16 \mathrm{~s}$ (range of median processing times: 5.25-25.42 s). Paired samples $t$ tests revealed that subjects answered tasks significantly faster ( $t_{12}=2.78, P=.017$, two-tailed) and more accurately $\left(t_{12}=3.51, P=0.004\right.$, two-tailed) in the SCP session (see Table 1). In the second measurement session no subject did recognize those task items which had already been presented during the first measurement session.
Questionnaire A. Tasks were generally judged to be easy and require little effort, which was not surprising considering the high task-specific ability of the subjects. None of the subjects had any difficulty to concentrate and most were highly motivated and convinced to have solved most of the tasks correctly. No significant differences $(P>0.3$ for all statistical tests) concerning these variables were observed when the answers after the SCP and the MRI sessions were compared using Wilcoxon signed rank tests.

Questionnaire B. Tasks were mainly solved by using one predominant strategy. In all subjects but one this was the dynamic visuospatial imagery strategy. Since this particular subject did not show any obvious 
a
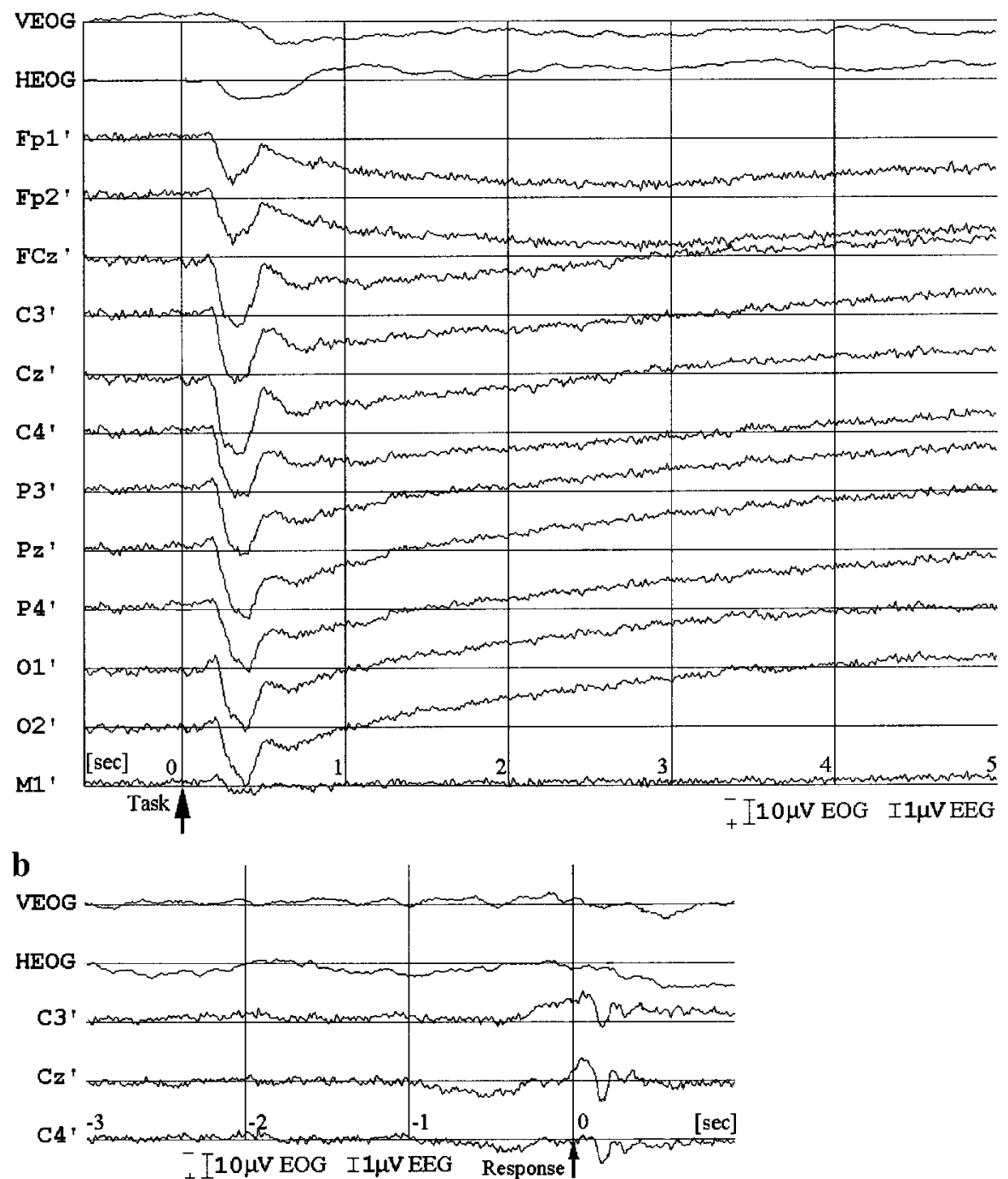

FIG. 4. Stimulus-linked (a) and response-linked (b) grand mean SCP waveforms of selected channels showing task-related activity changes. Task presentation and task answering are marked by arrows. Note the very similar SCP onset and time-course of the occipitoparietal and central channels.

difference in brain activity in comparison to the others, the results from this subject will not be treated separately. All subjects also used the verbal-analytical strategy occasionally. When using the visuospatial imagery strategy the subjects imagined movements of the cubes into a new orientation. However, they neither imagined themselves actively executing these movements nor did they imagine moving around the cubes to change their perspective. Imagined movements proceeded rather autonomously or "on their own," with the cubes usually moving as a whole. The mental images experienced during task processing were reported to be vivid and comparable to actual vision. When using the analytical strategy, subjects coded the spatial relations of the graphic elements on the two cubes and then compared these relations. These comparisons were ex- ecuted sequentially for each face of the cubes. In coding the spatial relations, subjects did not refer to their own position, but used an independent frame of reference. No significant differences were observed-neither for the imagery nor for the analytic strategy-when the answers given after the SCP and the MRI sessions were compared using Mann-Whitney $U$ tests $(P>.09$ for all statistical tests).

Additional informal reports of subjects during experimental debriefing indicated that task solving consisted of several steps including perceptual analysis of the cubes and the elements on their faces, the construction of a visual mental image of one of the cubes (in most trials, this was the cube presented on the left side), mental rotation (tilting) into supposed congruence with the other cube, and subsequent matching of 
the two cubes by comparing the location and orientation of the elements on their faces (see also Just and Carpenter, 1985).

\section{fMRI}

The fMRI grand mean revealed significant bilateral activity clusters in occipital and parietal cortex, precentral gyrus, medial superior frontal gyrus, dorsolateral prefrontal cortex and anterior insular cortex (see Fig. 2). Table 2 lists the neuroanatomical localization and consistency of these activity clusters across subjects. As Figure 2 shows, activity was most prominent and widespread in the parietal cortex, including the superior parietal lobe and intraparietal sulcus and partially extending into the inferior parietal lobe. The left- and right-hemispheric activity clusters in the precentral gyrus rostrally extended into the precentral sulcus, but their maximum and the majority of voxels were clearly located in the precentral gyrus and lateral BA 6 . The maximum and the majority of voxels of the activity cluster in the medial superior frontal gyrus were located in an area classifiable as rostral supplementary motor area or pre-SMA as opposed to SMA proper (Roland and Zilles, 1996; Matsuzaka et al., 1992). Activity also partially extended into the anterior cingulate. In addition, a number of anatomical regions were above threshold in either a single or a few maps only. These included gyrus lingualis, gyrus orbitofrontalis, posterior parts of gyrus temporalis inferioris, thalamus, and primary motor cortex.

In order to assess the onset and time course of the hemodynamic response function, signal time courses of selected activated pixels were plotted. After stimulus onset the hemodynamic response showed a delayed, but fairly constant increase with processing time and a peak around one to five seconds after task completion. Notably, the onset and time-course of the signal increase in lateral and medial premotor regions were very similar to those in parietal regions (see Fig. 3).

\section{$S C P s$}

The presentation of the task stimulus evoked a N100-like negative phasic ERP peaking around $120 \mathrm{~ms}$, which was focally localized over the occipito-parietal scalp. This component was followed by a phasic positive, P300-like deflection peaking at around $350 \mathrm{~ms}$ with a broadly distributed topography and a maximum at mediocentral recording sites. Following these transient potentials, sustained negative SCPs consistently (Table 3) developed over occipital, parietal, lateral central, and medial frontocentral regions, as well as less consistently over frontolateral regions. Visual inspection of waveforms suggested that negative SCPs started immediately after the P300-like component, i.e., around $550 \mathrm{~ms}$ for occipital and parietal and around $650 \mathrm{~ms}$ for central and frontocentral recording locations (see Fig. 4a). While the early phasic EEG components were not similar to fMRI results, SCPs indicated activity in similar regions as fMRI. The CSD maps (Fig. 5) showed focal current sinks over the parietal, lateral central, medial frontocentral, and lateral frontal regions. Less focal activity was observed over the occipital scalp. In order to assess task-related changes in slow potential amplitude independently of the early phasic potentials associated with task presentation and stimulus classification, we computed the difference between SCP amplitude at latencies of $5 \mathrm{~s}$ vs one second after stimulus presentation. This revealed that the highest increase in negativity occurred at the parietal leads $(-15.97$ $\mu \mathrm{V}$ for electrode $\mathrm{Pz}$ '), and that lateral central and frontocentral electrodes showed a smaller, but still considerable increase in slow potential amplitude $(-10.79 \mu \mathrm{V}$ for electrode Cz'; see also Fig. 4a). A number of electrodes showed negligible or positive amplitude changes (see electrodes M1 or Fp1, Fp2, respectively, in Fig. 4a).

Response-linked averages yielded a pattern of activity that was almost identical to stimulus-linked averages up to about $200-300 \mathrm{~ms}$ prior to the response. During this interval, a Bereitschaftspotential-like component was observed over the central region, and the current sink over the right lateral central region almost disappeared, while the current sink over the left hemisphere remained largely unchanged (see Figs. 4b and $5 \mathrm{~d})$.

Coregistration of SCP electrodes and structural brain images showed that on average the electrodes C3' and C4' were positioned 4.4 and $4.2 \mathrm{~cm}$ anterior to the lateral central sulcus and the electrodes $\mathrm{Cz}$ ' and FCz' were located 5.4 and $8.6 \mathrm{~cm}$ anterior to the medial central sulcus.

\section{DISCUSSION}

In the recent literature on functional neuroimaging some controversy has arisen as to whether or not dynamic visuospatial imagery is associated with activity in higher-order human motor areas. Although behavioral studies and theoretical accounts of the phenomenon of mental rotation suggest the involvement of the premotor cortex, two recent PET studies (Kosslyn et al., 1998; Harris et al., 2000) and the latest fMRI study (Jordan et al., 2001) did not detect any such activity. On the other hand, premotor activity has repeatedly been shown using fMRI (e.g., Richter et al., 2000; Cohen et al., 1996; Tagaris et al., 1998), although not always in all of the subjects investigated. A major aim of the present study has been to assess premotor activity during the processing of a visuospatial imagery task using two complementary brain imaging methods.

Our results clearly support the hypothesis that the premotor cortex is active during task processing. fMRI provided a precise three-dimensional localization of task-related activities in a distributed network consist- 
ing of occipital, parietal, dorsolateral prefrontal, anterior insular cortex, and lateral and medial premotor cortex. As Table 2 shows, these activities were highly consistent between subjects. The SCP results were very comparable to the fMRI results. Despite the lower spatial resolution of SCPs, activity was also indicated in the occipital, parietal, and lateral frontal regions. Over the central region, the CSD maps revealed three clearly distinguishable current sinks that show a similar activity pattern as the fMR images. Although for a number of reasons the ability to localize focal brain activity by means of surface recordings is inherently limited, the position of the central and precentral electrodes clearly suggests that this activity originated in the premotor rather than the primary motor cortex. This is also corroborated by the response-linked average showing a Bereitschaftspotential-like component, which is thought to reflect activity in premotor structures (see, e.g., Cui et al., 1999; Gerloff et al., 1996; Ball et al., 1999).

A very early onset of processing around $650 \mathrm{~ms}$ was revealed by the steady increase in relative SCP negativity starting around this time. This onset was similar to that for the occipitoparietal leads. However, it must be noted that the measured potentials became negative only around 2 to $3 \mathrm{~s}$ after task presentation. As demonstrated by Heil et al. (1996; see also Bajric et al., 1999), this seems to be due to a superposition of potentials associated with character recognition and classification which evoke a slow positive deflection of considerable amplitude, as well as of a slow negative potential with lower amplitude related to mental rotation/object transformation. As a result of this superposition and the lower relative amplitude of the negative potential component, the potential measured became negative only after a delay of approximately 1-2 s.

Similar to the parietal cortex, the premotor cortex was active during the entire time of task processing. This was indicated by the time-course of SCPs and of fMRI signal changes. Thus it seems likely that premotor activity is directly related to task processing and not only to peripheral aspects of the task, a fact that is also suggested by the time-resolved analysis of Richter et al. (2000). Although exact response times were rarely reported in earlier studies investigating mental rotation, they were rather short, ranging from approximately $1.5 \mathrm{~s}$ (Tagaris et al., 1998) to $4 \mathrm{~s}$ (Carpenter et al., 1999) or $6 \mathrm{~s}$ (Richter et al., 2000). Even in the latter two studies, tasks with a low angular disparity between objects could be answered within 1 or $2 \mathrm{~s}$. Several studies investigating single finger movements (Cunnington et al., 1999; Richter et al., 1997; Humberstone et al., 1997) revealed signal increases in premotor and primary motor cortex around $3 \mathrm{~s}$ before movement onset to $1 \mathrm{~s}$ afterwards. Hence, in earlier studies premotor activity might have been interpreted as reflecting the anticipation, preparation, and execution of finger movements for task answering. This interpretation can be excluded by our study in which we obtained response times of approximately 16 and $12 \mathrm{~s}$, respectively.

Based on earlier PET and fMRI studies, it may be argued that premotor blood flow or oxygenation increases during mental rotation are due to increased activity of inhibitory rather than excitatory neurons. This explanation can now be ruled out, since SCPs provide a more direct assessment of neural activity than hemodynamic indicators of activity. In particular, there is general agreement that-with some rare exceptions-surface negative changes in SCP amplitude relative to a prestimulus baseline indicate an increase in excitatory postsynaptic potentials (EPSPs) of apical cortical dendrites, while positive SCPs are related to decreased input to these dendrites and/or an increase in inhibitory PSPs (Bauer, 1998; Rösler et al., 1997; Birbaumer et al., 1990).

We decided to analyze fMRI data using parametric statistics. The application of non-parametric statistics in the analysis of brain images has repeatedly been suggested as a more valid alternative (see, e.g., Holmes et al., 1996) with the main intention of avoiding the approximations and assumptions with respect to the distribution of data required by parametric statistics. Violations of these assumptions might lead to noisy statistic maps that are only of limited validity. However, several observations indicate that the statistical analysis we performed has yielded valid results.

First, it has been argued that the main reason for violations of the distributional assumptions of parametric statistics is a small number of scans and subjects (Holmes et al., 1996). In the present study we investigated a comparatively large number of subjects (see, e.g., Vitouch and Glück, 1997, for a comparison of the sample sizes of neuroimaging studies). We also used single-trial analysis and calculated a $t$ value for every trial of every subject, which resulted in a total of about 550 single-trial results in thirteen subjects that were used for analysis. Second, a reanalysis of our data with an exploratory data analysis technique (fuzzy cluster analysis; Windischberger et al., 1999) indicated activity in very similar regions as the parametric analysis performed. Third, the combination of SCPs and fMRI yielded a mutual corroboration of results (which was, however, restricted to cortical activity).

Another topic that has been much discussed in the statistical analysis of brain imaging data has to do with the thresholding of statistical maps. However, the decision about how this thresholding should be performed in order to separate "true" from "false" activity is not trivial. This partly results from the difficulties associated with the conversion of statistics to probability values that have been corrected for multiple comparisons. Several approaches have been conceived to solve this problem. On the one hand, it would be fea- 


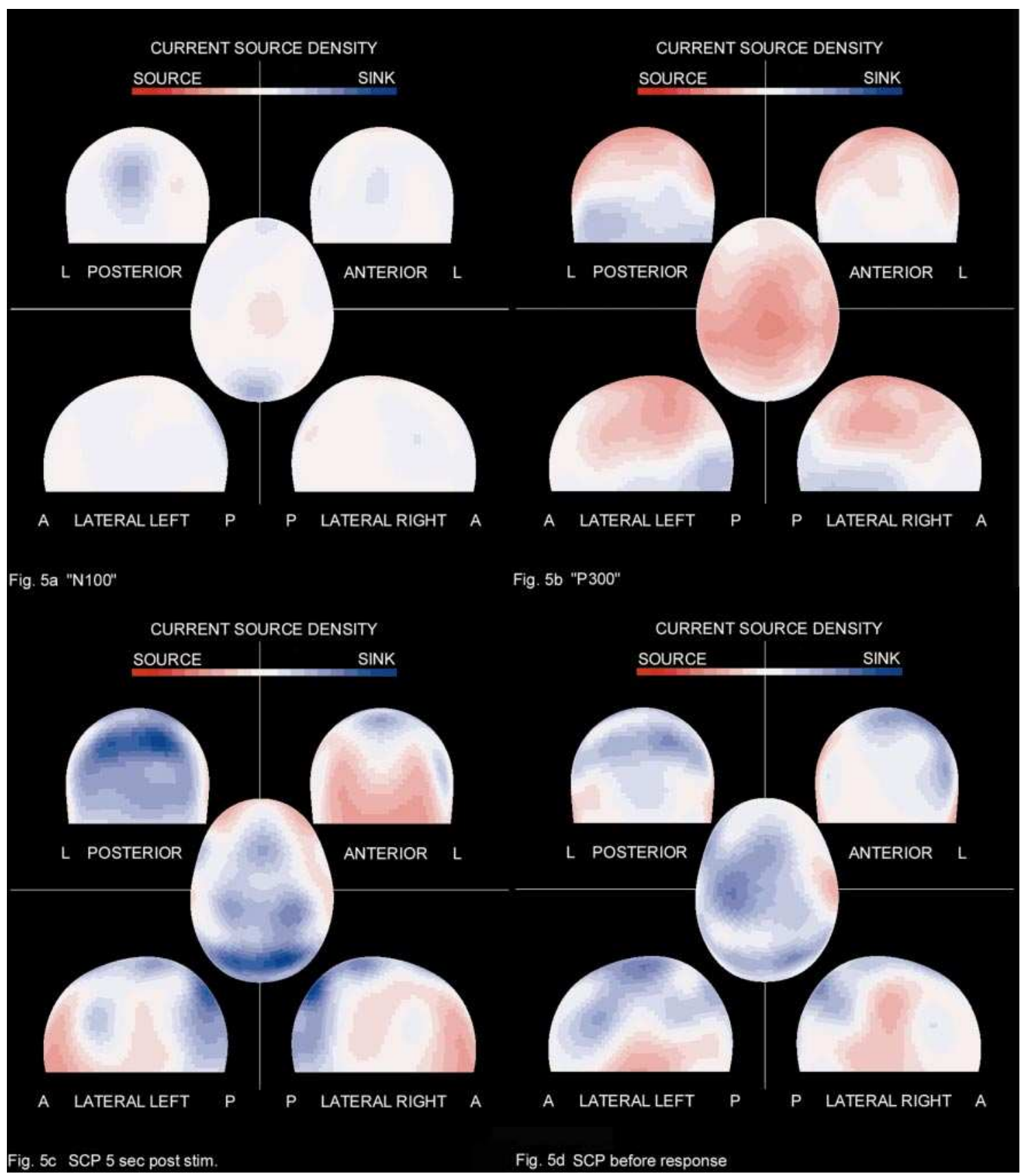

FIG. 5. Color-coded grand mean CSD maps $120 \mathrm{~ms}$ after task presentation (a), $350 \mathrm{~ms}$ after task presentation (b), $5 \mathrm{~s}$ after task presentation (c), and before response execution (d). Current sources are coded in red and current sinks are coded in blue. Note the similarity of $\mathrm{c}$ and the fMRI map (Fig. 2). Activity in the parietal cortex is clearly revealed and the three distinct focal current sinks over the central region are most likely related to activity in premotor structures.

sible to use no inference statistic at all (i.e., no reference to $P$ values), but to infer "significance" from a thorough descriptive analysis of the data only. However, this does not circumvent the problem that data have to be thresholded in a certain way-either implicitly by the researcher who decides which descriptive statistic is indicative of activity and which is not, or by the rather arbitrary selection of a threshold. More frequently, $P$ values are corrected for multiple compari- sons (either using Bonferroni correction or the framework of random Gaussian fields, as implemented in the SPM software). We had strong hypotheses that there is task-related activity in several regions of the brain (with evidence coming both from previously published fMRI studies, previous SCP experiments-e.g., Lamm et al., 1999 - and the SCP data acquired in this study). In the case of such a priori hypotheses, Bonferroni correction for the whole image volume might have been 
overly conservative. Thus, we chose to perform no correction for multiple comparisons, but used a rather high threshold level $(P=0.00001$; which is a much more conservative threshold than the one used by comparable single-trial studies, e.g., Humberstone et al., 1997) to reduce the probability of obtaining a high amount of false positives. In addition, it should be noted that the spatial extent of our activity clusters (especially in parietal and lateral premotor cortex) was rather large. Although it is possible that single voxels were falsely indicated as being active, it seems highly unlikely that all voxels in these large active areas could be false positives. Hence, although we concede that single "significant" voxels might not reflect true activity, the main inference that there is activity in parietal and premotor regions during task-processing seems to be well-justified.

As in all tasks requiring dynamic visuospatial imagery, the subjects had to visually scan spatial objects via movements of their eyes. As demonstrated by a considerable number of PET and fMRI studies, saccade execution, and preparation, as well as foveal fixation lead to activity in brain areas very similar to those active in our study (see, e.g., Anderson et al., 1994; Perry and Zeki, 2000; Petit et al., 1999, Petit and Haxby, 1999). The same applies to visuospatial attention, which is also required in visuospatial imagery where attention has to be shifted toward specific salient features of the visuospatial stimuli (see, e.g., Corbetta et al., 1998; Corbetta, 1998; Nobre et al., 1997, 2000). Recent intracortical recordings of activity in human frontal eye fields (FEFs) have also shown responses to extrafoveally and foveally presented stimuli in the FEF even though saccadic eye movements had to be suppressed (Blanke et al., 1999). While foveal fixation can be largely ruled out as an explanation for parietal and premotor activity in our study since the subjects had to fixate a crosshair during the prestimulus epoch, part of the activity observed might be related to oculomotor scanning and visuospatial attention.

However, several arguments suggest that this activity cannot be exclusively related to such processes. Although the lateral premotor activity clusters in our study partially extended into the regions known as the frontal eye fields (FEF), stereotactic coordinates of the FEFs as well as of the overlapping regions active during covert attention are different from our activity maxima (see, e.g., Paus, 1996, and the recent review by Petit et al., 1999, which reports mean coordinates of $36 /-9 / 45$ for the left FEF and of $-35 /-11 / 46$ for the right $\mathrm{FEF}$, respectively). In addition, the spatial extent of activity clusters related to eye movements is usually much smaller than that observed in our study in which a rather large part of the lateral precentral gyrus was active. A similar argument applies to the parietal areas where activity related to eye-movements is mainly confined to the intraparietal sulcus. Furthermore, a recent
fMRI study by Carpenter et al. (1999) specifically addressed the issue of how much of the activity during visuospatial imagery can be attributed to saccadic eye movements. The authors contrasted a mental rotation task with a task requiring continuous saccadic scanning of a two-dimensional grid. Although the latter evoked significant activity in similar parietal and premotor regions as the mental rotation, both the amplitude and the spatial extent of this activity were considerably smaller than during mental rotation. Thus, even though there may be an overlap between activity related to oculomotor processing and visuospatial attention on the one hand and dynamic visuospatial imagery on the other, it may be concluded that the latter evokes additional neural processing in both parietal and lateral premotor areas.

A more complicated picture, however, arises for the medial premotor activity. The SMA coordinates related to eye movements and visuospatial attention reported by, e.g., Perry and Zeki (2000) or Corbetta et al. (1998), were located much more anterior than our activity. On the other hand, several studies (Nobre et al., 2000, Anderson et al., 1990, Petit and Haxby, 1999, O'Driscoll et al., 2000) reported more posterior coordinates. SMA activity in our study might also be related to working memory demands, as Petit et al. (1998) have shown activity in a similar region during memorization of spatial patterns. As for the activity in the insular cortex, so far no study has reported any activity in this area during mental rotation of 3-D geometrical objects. However, it seems well established that the insular cortex is involved in the control of eye movements. Thus it remains to be investigated whether insular activity is related to task-relevant processing or merely to eye-movement control.

\section{Functional Equivalence of Overt and Covert Object Manipulation}

Regarding our results and earlier findings, one might speculate as to the reasons for premotor involvement in a task which does not require continuous motor execution. Such activity might be related to motor imagery and associated kinesthetic feelings of limb or body movements (Jeannerod, 1994; Lotze et al., 1999; Porro et al., 1996; Pfurtscheller and Neuper, 1997). However, this would imply that subjects solved the tasks from an internal perspective. This is in contrast to introspective reports of our subjects who neither reported imagining themselves moving the cubes nor moving themselves around the cubes. Likewise in informal discussions during experimental debriefing no subjects reported imagining their hands or other body parts tilting or rotating the cubes.

Wexler et al. (1998) suggested that the specific interactions of manual and mental rotation showed that mental rotation involves covert simulation of motor 
rotation. This would imply mechanisms of visuomotor anticipation, i.e., mechanisms which allow the observer to anticipate the visual consequences of a motor action. A large reciprocally connected neo-cortical network involving parietal (BA 7) and premotor areas (BA 6 ) is thought to be essential for planning and control of movements and anticipation of their consequences. This might explain the very similar time-courses of activity in these structures in the present study (Jeannerod, 1994; Johnson et al., 1996; Andersen et al., 1997).

Another explanation of parietal and premotor activity might be that it is related to the observation of the rotational movement of the cubes. Several behavioral studies have demonstrated an interference between perception of rotary motion and mental rotation (the so-called rotation aftereffect; Corballis and Corballis, 1993; Corballis and McLaren, 1982). In fact, there is some evidence that the observation of movements and gestures is accompanied by activity in premotor areas (see Decety and Grèces, 1999, for a recent review). Also, mirror neurons of primary motor neurons have been detected in the rostral part of the ventral premotor cortex (area F5) of macaque monkey which are active during the observation of extraneous movements (Rizzolatti and Arbib, 1998). However, it remains to be shown whether these findings are transferable to the merely imagined observation of movements of a nonliving object, since a recent fMRI study (Barnes et al., 2000) did not find any activity in premotor regions when subjects passively observed the rotation of Shepard-Metzler figures.

The "simulation" and the "observation" approach might partially explain the occurrence of premotor activity during dynamic visuospatial imagery. However, neither approach considers the fact that mental rotation is not the only process required when two visuospatial objects are compared. Several other processes (object encoding, mental image generation, stimulus matching) are equally important. These processes involve neither the anticipation nor the observation of movements. A separation of these different task aspects is difficult both with the task paradigm we used and with the Shepard-Metzler figures. Nevertheless the early onset of premotor SCPs, their continuous increase until task response as well as the early onset of the hemodynamic response in premotor cortex observed in our study and in the time-resolved fMRI study by Richter et al. (2000) suggest that the premotor cortex is also active during visuoperceptual analysis, mental image generation, and object matching.

Thus another feasible, but rather speculative explanation for the involvement of the premotor cortex in dynamic visuospatial imagery is that motor structures are activated whenever extended visuospatial information processing is required. Just as perception and imagery are tightly coupled and show a vast overlap in the brain regions supporting their functions (see Kosslyn, 1994, for an extensive review and evidence), this might also be true of motor actions and spatial processing. The close relationship between motion and space becomes especially evident in the ontogenetic development of mammals. There, action and spatial perception are coupled inseparably since there is no perception of space without movement and no movement without feedback about the spatial aspects of the movement. The hypothesis that spatial perception and imagery per se activate premotor structures is supported by two recent fMRI studies of visuospatial processing and the recognition of 3-D objects. Shen et al. (1999) asked subjects to compare the spatial location of sequentially presented simple geometric objects. They found activity in premotor structures although the task required no concurrent motor output. Sugio et al. (1999) detected activity in medial and lateral BA 6 when asking subjects to identify objects presented in noncanonical orientations.

However, these results like those of all of the mental rotation experiments so far only indicate that there is a correlation between visuospatial processing and activity in higher-order motor areas. They do not provide any direct explanation or assessment of the specific role or function of these areas in visuospatial imagery and perception. For example, we cannot be certain that these regions are functionally relevant for the visuospatial transformations initiated by the tasks. It could well be that they do not have a specific functional role in task processing and are only coactivated by default (e.g., because objects that can be grabbed are presented, which, in the monkey, activates ventral premotor cortex even if no subsequent grasping movement is required; Murata et al., 1997; Rizzolatti et al., 1988).

For now, however, we can conclude that visuospatial imagery consistently recruits a distributed network of cortical structures including the premotor cortex. Further experiments that separate the visuoperceptual analysis of objects, visual mental image generation and buffering, and mental rotation and object matching, and that vary the amount of dynamic and static visuospatial information processing required are necessary to assess the functional role of premotor activity more specifically.

\section{ACKNOWLEDGMENTS}

This work was funded in part by grants 7174 and 8184 of the Jubiläumsfonds der Oesterreichischen National Bank. We are very grateful to two anonymous reviewers for their helpful comments on an earlier version of this paper.

\section{REFERENCES}

Andersen, R. A., Snyder, L. H., Bradley, D. C., and Xing, J. 1997. Multimodal representation of space in the posterior parietal cortex 
and its use in planning movements. Annu. Rev. Neurosci. 20: 303-320.

Anderson, T. J., Jenkins, I. H., Brooks, D. J., Hawken, M. B., Frackowiak, R. S. J., and Kennard, C. 1994. Cortical control of saccades and fixation in man. A PET study. Brain 117: 1073-1084.

Annett, M. 1985. Left, Right, Hand, and Brain: The Right Shift Theory. Erlbaum, London.

Babiloni, F., Babiloni, C., Carducci, F., Fattorini, L., Onorati, P., and Urbao, A. 1996. Spline laplacian estimate of EEG potentials over a realistic magnetic resonance-constructed head surface model. Electroencephalogr. Clin. Neurophysiol. 98: 363-373.

Bain, A. 1855. The Senses and the Intellect. Parker, London.

Bajric, J., Rösler, F., Heil, M., and Hennighausen, E. 1999. On separating processes of event categorization, task preparation, and mental rotation proper in a handedness recognition task. Psychophysiology 36: 399-408.

Ball, T., Schreiber, A., Feige, B., Wagner, M., Lücking, C. H., and Kristeva-Feige, R. 1999. The role of higher-order motor areas in voluntary movement as revealed by high-resolution EEG and fMRI. Neuroimage 10: 682-694.

Barnes, J., Howard, R. J., Senior, C., Brammer, M., Bullmore, E. T., Simmons, A., Woodruff, P., and David, A. S. 2000. Cortical activity during rotational and linear transformations. Neuropsychologia 38: $1148-1156$.

Bauer, H. 1998. Slow potential topography. Behav. Res. Methods Instruments Comput. 30: 20-33.

Bauer, H., Lamm, C., Holzreiter, S., Holländer, I., Leodolter, U., and Leodolter, M. 2000. Measurement of 3-D electrode coordinates by means of a 3-D photogrammetric head digitizer. Neuroimage 11: S461.

Bauer, H., Steinringer, H., and Schock, P. 1980. A new highly sensitive DC-amplifier for steady biopotential recording. Archiv. Psychol. 133: 333-337.

Birbaumer, N., Elbert, T., Canavan, A. G. M., and Rockstroh, B. 1990. Slow potentials of the cerebral cortex and behavior. Physiol. Rev. 70: 1-41.

Blanke, O., Morand, S., Thut, G., Michel, C. M., Spinelli, L., Landis, T., and Seeck, M. 1999. Visual activity in the human frontal eye field. Neuroreport 10: 925-930.

Carpenter, P. A., Just, M. A., Keller, T. A., and Eddy, W. 1999. Graded functional activation in the visuospatial system with the amount of task demand. J. Cogn. Neurosci. 11: 9-21.

Cohen, D., and Kubovy, M. 1993. Mental rotation, mental representation, and flat slopes. Cogn. Psychol. 25: 351-382.

Cohen, M. S., Kosslyn, S. M., Breiter, H. C., DiGirolamo, G. J., Thompson, W. L., Anderson, A. K., Bookheimer, S. Y., Rosen, B. R., and Belliveau, J. W. 1996. Changes in cortical activity during mental rotation: A mapping study using functional MRI. Brain 119: $89-100$.

Cooper, L. A., and Shepard, R. N. 1984. Turning something over in the mind. Sci. Am. 251: 106-114.

Corballis, M. C., and McLaren, R. 1982. Interaction between perceived and imagined rotation. J. Exp. Psychol. Hum. Percept. Perform. 8: 215-224.

Corballis, M. C., Zebrodoff, N. J., Shetzer, L. I., and Butler, B. B. 1978. Decisions about identity and orientation of rotated letters and digits. Memory Cogn. 6: 98-107.

Corballis, P. M., and Corballis, M. C. 1993. How apparent motion affects mental rotation: Push or pull? Memory Cogn. 21: 458-466.

Corbetta, M. 1998. Frontoparietal cortical networks for directing attention and the eye to visual locations: Identical, independent, or overlapping neural systems? Proc. Natl. Acad. Sci. USA 95: 831838 .
Corbetta, M., Akbudak, E., Conturo, T. E., Snyder, A. Z., Ollinger, J. M., Drury, H. A., Linenweber, M. R., Petersen, S. E., Raichle, M. E., Van Essen, D. C., and Shulman, G. L. 1998. A common network of functional areas for attention and eye movements. Neuron 21: 761-773.

Cui, R. Q., Hutter, D., Lang, W., and Deecke, L. 1999. Neuroimage of voluntary movement: Topography of the Bereitschaftspotential, a 64-channel DC current source density study. Neuroimage 9: 124134.

Cunnington, R., Windischberger, C., and Moser, E. 1999. High temporal resolution fMRI reveals details of hemodynamic response timecourses in different motor cortical areas for single actions. MAGMA 8: 163-164.

Decety, J., and Grèzes, J. 1999. Neural mechanisms subserving the perception of human actions. Trends Cogn. Sci. 3: 172-178.

Evans, A. C., Collins, D. L., Mills, S. R., Brown, E. D., Kelly, R. L., and Peters, T. M. 1993. 3-D statistical neuroanatomical models from 305 MRI volumes. Proceedings IEEE-Nuclear Science Symposium and Medical Imaging Conference, pp. 1813-1817.

Friston, K. J., Holmes, A. P., and Worsley, K. J. 1999. How many subjects constitute a study? Neuroimage 10: $1-5$.

Friston, K. J., Holmes, A. P., Worsley, K. J., Poline, J. P., Frith, C. D., and Frackowiak, R. S. J. 1995. Statistical parametric maps in functional imaging: A general linear approach. Hum. Brain Mapp. 2: $189-210$.

Georgopoulos, A. P., and Pellizzer, G. 1995. The mental and the neural: Psychological and neural studies of mental rotation and memory scanning. Neuropsychologia 33: 1531-1547.

Gerloff, C., Grodd, W., Altenmüller, E., Kolb, R., Naegele, T., Klose, U., Voigt, K., and Dichgans, J. 1996. Coregistration of EEG and fMRI in a simple motor task. Hum. Brain Mapp. 4: 199-209.

Gittler, G. 1990. Dreidimensionaler Würfeltest (3DW): Ein Raschskalierter Test zur Messung des räumlichen Vorstellungsvermögens, Theoretische Grundlagen und Manual. Beltz Test, Weinheim.

Grafton, S. T., Fadiga, L., Arbib, M. A., and Rizzolatti, G. 1997. Premotor cortex activation during observation and naming of familiar tools. Neuroimage 6: 231-236.

Gulliksen, H. 1965. Theory of Mental Tests. Wiley, New York.

Haier, R. J., Siegel, B., Nuechterlein, K. H., Hazlett, E., Wu, J. C., Paek, J., Browning, H. L., and Buchsbaum, M. S. 1988. Cortical glucose metabolic rate correlates of abstract reasoning and attention studied with positron emission tomography. Intelligence 12: 199-217.

Harris, I. M., Egan, G. F., Sonkkila, C., Tochon-Danguy, H. J., Paxinos, G., and Watson, J. D. 2000. Selective right parietal lobe activation during mental rotation: A parametric PET study. Brain 123: 65-73.

Heil, M., Bajric, J., Rösler, F., and Hennighausen, E. 1996. Eventrelated potentials during mental rotation: Dissentangling the contributions of character classification and image transformation. J. Psychophysiol. 10: 326-335.

Holmes, A. P., Blair, R. C., Watson, J. D., and Ford, I. 1996. Nonparametric analysis of statistic images from functional mapping experiments. J. Cereb. Blood Flow Metab. 16: 7-22.

Humberstone, M., Sawle, G. V., Clare, S., Hykin, J., Coxon, R., Bowtell, R., MacDonald, I., and Morris, P. G. 1997. Functional magnetic resonance imaging of single motor events reveals human presupplementary motor area. Ann. Neurol. 42: 632-637.

Intions-Peterson, M. J. 1983. Imagery paradigms: How vulnerable are they to experimenter's expectations? J. Exp. Psychol. Hum. Percept. Perform. 9: 394-412.

James, W. 1890. The Principles of Psychology, MacMillan, London. 
Jasper, H. H. 1958. The 10-20 electrode system of the International Federation. Electroencephalogr. Clin. Neurophysiol. 10: 370-375.

Jeannerod, M. 1994. The representing brain: Neural correlates of motor intention and imagery. Behav. Brain Sci. 17: 187-202.

Johnson, P. B., Ferraina, S., Bianchi, L., and Caminiti, R. 1996. Cortical networks for visual reaching-physiological and anatomical organization of frontal and parietal lobe arm regions. Cereb. Cortex 6: 102-119.

Jordan, K., Heinze, H.-J., Lutz, K., Kanowski, M., and Jäncke, L. 2001. Cortical activations during the mental rotation of different visual objects. Neuroimage 13: 143-152.

Just, M. A., and Carpenter, P. A. 1985. Cognitive coordinate systems: Accounts of mental rotation and individual differences in spatial ability. Psychol. Rev. 92: 137-172.

Kosslyn, S. M. 1994. Image and Brain. The Resolution of the Imagery Debate. MIT Press/A Bradford Book, Cambridge, MA.

Kosslyn, S. M., Digirolamo, G. J., Thompson, W. L., and Alpert, N. M. 1998. Mental rotation of objects versus hands: Neural mechanisms revealed by positron emission tomography. Psychophysiology 35: 151-161.

Lamm, C., Bauer, H., Vitouch, O., Durec, S., Gstättner, R., and Gronister, S. 2001. Restriction of task processing time affects cortical activity during processing of a cognitive task: An eventrelated slow cortical potential study. Cogn. Brain Res. 10: 275282 .

Lamm, C., Bauer, H., Vitouch, O., and Gstättner, R. 1999. Differences in the ability to process a visuospatial task are reflected in event-related slow cortical potentials of human subjects. Neurosci. Lett. 269: 137-140.

Lamm, C., Windischberger, C., Leodolter, U., Moser, E., and Bauer, H. 2000. High accuracy of matching spline-interpolated EEG- with MRl-derived head surfaces. Proc. ISMRM 8: 859.

Lancaster, J., Kochunov, P., Woldorff, M., Liotti, M., Parsons, L., Rainey, L., Nickerson, D., and Fox, P. 2000. Automatic talairach labels for functional activation sites. Neuroimage 11: S483.

Lotze, M., Montoya, P., Erb, M., Hulsmann, E., Flor, H., Klose, U., Birbaumer, N., and Grodd, W. 1999. Activation of cortical and cerebellar motor areas during executed and imagined hand movements: An fMRI study. J. Cogn. Neurosci. 11: 491-501.

Matsuzaka, Y., Aizawa, H., and Tanji, J. 1992. A motor area rostral to the supplementary motor area (presupplementary motor area) in the monkey: Neuronal activity during a learned motor task. J. Neurophysiol. 68: 653-662.

Murata, A., Fadiga, L., Fogassi, L., Gallese, V., Raos, V., and Rizzolatti, G. 1997. Object representation in the ventral premotor cortex (area F5) of the monkey. J. Neurophysiol. 78: 2226-2230.

Nobre, A. C., Gitelman, D. R., Dias, E. C., and Mesulam, M. M. 2000. Covert visual spatial orienting and saccades: Overlapping neural systems. Neuroimage 11: 210-216.

Nobre, A. C., Sebestyen, G. N., Gitelman, D. R., Mesulam, M. M., Frackowiak, R. S. J., and Frith, C. D. 1997. Functional localization of the system for visuospatial attention using positron emission tomography. Brain 120: 515-533.

Nunez, P. 1989. Estimation of large scale neocortical source activity with EEG surface Laplacians. Brain Topogr. 2: 141-154.

Nunez, P. L., Silberstein, R. B., Cadusch, P. J., Wijesinghe, R. S., Westdorp, A. F., and Srinivasan, R. 1994. A theoretical and experimental study of high resolution EEG based on surface Laplacians and cortical imaging. Electroencephalogr. Clin. Neurophysiol. 90: 40-57.

O’Driscoll, G. A., Wolff, A.-L. V., Benkelfat, C., Florencio, P. S., Lal, S., and Evans, A. C. 2000. Functional neuroanatomy of smooth pursuit and predictive saccades. Neuroreport 11: 1335-1340.
Paus, T. 1996. Location and function of the human frontal eye-field: A selective review. Neuropsychologia 34: 475-483.

Pellizzer, G., and Georgopoulos, A. P. 1993. Common processing constraints for visuomotor and visual mental rotations. Exp. Brain Res. 93: 165-172.

Perry, R. J., and Zeki, S. 2000. The neurology of saccades and covert shifts in spatial attention. An event-related fMRI study. Brain 123: $2273-2288$.

Petit, L., Courtney, S. M., Ungerleider, L. G., and Haxby, J. V. 1998. Sustained activity in the medial wall during working memory delays. J. Neurosci. 18: 9429-9437.

Petit, L., Dubois, S., Tzourio, N., Dejardin, S., Crivello, F., Michel, C., Etard, O., Denise, P., Roucoux, A., and Mazoyer, B. 1999. PET study of the human foveal fixation system. Hum. Brain Mapp. 8: 21-43.

Petit, L., and Haxby, J. V. 1999. Functional anatomy of pursuit eye movements in humans as revealed by fMRI. J. Neurophysiol. 81: $463-471$.

Pfurtscheller, G., and Neuper, C. 1997. Motor imagery activates primary sensorimotor area in humans. Neurosci. Lett. 239: 65-68.

Picton, C., and Hillyard. 1974. Cephalic skin potentials in electroencephalography. Electroencephalogr. Clin. Neurophysiol. 33: 419-424.

Porro, C. A., Francescato, M. P., Cettolo, V., Diamond, M. E., Baraldi, P., Zuiani, C., Bazzocchi, M., and di Prampero, P.E. 1996. Primary motor and sensory cortex activation during motor performance and motor imagery: A functional magnetic resonance imaging study. J. Neurosci. 16: 7688-7698.

Prinz, W. 1997. Perception and action planning. Eur. J. Cogn. Psychol. 9: 129-154.

Rasch, G. 1980. Probabilistic Models for Some Intelligence and Attainment Tests. The University of Chicago Press, Chicago.

Richter, W., Andersen, P. M., Georgopoulos, A. P., and Kim, S. G. 1997. Sequential activity in human motor areas during a delayed cued finger movement task studied by time-resolved fMRI. Neuroreport 8: $1257-1261$.

Richter, W., Somorjai, R., Summers, R., Menon, R. S., Gati, J. S., Georgopoulos, A. P., Tegeler, C., Ugurbil, K., and Kim, S.-G. 2000. Motor area activity during mental rotation studied by time-resolved single-trial fMRI. J. Cogn. Neurosci. 12: 310-320.

Rizzolatti, G., and Arbib, M. A. 1998. Language within our grasp. Trends Neurosci. 21: 188-194.

Rizzolatti, G., Camarda, R., Fogassi, L., Gentilucci, M., Luppino, G., and Matelli, M. 1988. Functional organization of inferior area 6 in the macaque monkey. II. Area F5 and the control of distal movements. Exp. Brain Res. 71: 491-507.

Roland, P. E., and Zilles, K. 1996. Functions and structures of the motor cortices in humans. Curr. Opin. Neurobiol. 6: 773-781.

Rösler, F., Heil, M., and Röder, B. 1997. Slow negative brain potentials as reflections of specific modular resources of cognition. Biol. Psychol. 45: 109-141.

Scheerer, E. 1984. Motor theories of cognitive structure: A historical review. In Cognition and Motor Processes (W. Prinz and A. F. Sanders, Eds.), pp. 77-98. Springer-Verlag, Berlin.

Schmidt, K. H., and Metzler, P. 1992. Wortschatztest (WST), Beltz Test, Weinheim.

Shen, L., Xiaoping, H., Yacoub, E., and Ugurbil, K. 1999. Neural correlates of visual form and visual spatial processing. Hum. Brain Mapp. 8: 60-71.

Shepard, R. N., and Metzler, J. 1971. Mental rotation of threedimensional objects. Science 171: 701-703.

Srinivasan, R., Nunez, P. L., Tucker, D. M., Silberstein, R. B., and Cadusch, P. J. 1996. Spatial sampling and filtering of EEG with spline laplacians to estimate cortical potentials. Brain Topogr. 8: $355-366$. 
Srinivasan, R., Tucker, D. M., and Murias, M. 1998. Estimating the spatial nyquist of the human EEG. Behav. Res. Methods Instr. Comput. 30: 8-19.

Stephenson, W., and Gibbs, F. 1951. A balanced non-cephalic electrode reference. Electroencephalogr. Clin. Neurophysiol. 3: 237240.

Sugio, T., Inui, T., Matsuo, K., Matsuzawa, M., Glover, G. H., and Nakai, T. 1999. The role of the posterior parietal cortex in human object recognition: A functional magnetic resonance imaging study. Neurosci. Lett. 276: 45-48.

Tagaris, G. A., Kim, S.-G., Strupp, J. P., Andersen, P., Ugurbil, K., and Georgopoulos, A. P. 1997. Mental rotation studied by funtional magnetic resonance imaging at high field (4 Tesla): Performance and cortical activation. J. Cogn. Neurosci. 9: 419-432.

Talairach, J., and Tournoux, P. 1988. Co-planar Stereotaxic Atlas of the Human Brain. Thieme Medical Publishers, New York.

Tarr, M. J., and Pinker, S. 1989. Mental rotation and orientationdependence in shape recognition. Cogn. Psychol. 21: 233-282.

Vitouch, O., Bauer, H., Gittler, G., Leodolter, M., and Leodolter, U. 1997. Cortical activity of good and poor spatial test performers during spatial and verbal processing studied with Slow Potential Topography. Int. J. Psychophysiol. 27: 183-199.

Voyer, D., Voyer, S., and Bryden, M. P. 1995. Magnitude of sex differences in spatial abilities: A meta-analysis and consideration of critical variables. Psychol. Bull. 117: 250-270.

Weimer, W. B. 1977. A conceptual framework for cognitive psychology: Motor theories of the mind. In Perceiving, Acting, and Knowing (R. Shaw and J. Bransford, Eds.), pp. 267-311. Erlbaum, Hillsdale.

Wexler, M., Kosslyn, S. M., and Berthoz, A. 1998. Motor processes in mental rotation. Cognition 68: 77-94.

Windischberger, W., Lamm, C., Bauer, H., and Moser, E. 1999. Paradigm-free fuzzy cluster analysis of a mental rotation paradigm at 3 T. MAGMA 11(Suppl.): 68 .

Wohlschläger, A., and Wohlschläger, A. 1998. Mental and manual rotation. J. Exp. Psychol. Hum. Percept. Perform. 24: 397-412.

Woods, R. P., Grafton, S. T., Holmes, C. J., Cherry, S. R., and Mazziotta, J. C. 1998. Automated image registration: I. General methods and intrasubject, intramodality validation. J. Comput. Assist. Tomogr. 22: 141-154. 